The International Otter Survival Fund (IOSF) has been holding a series of workshops to train the next generation of otter researchers in Asia, where there is a serious problem with illegal trade in otters, both for furs and as pets. The workshops cover field techniques for otter research, public awareness programmes, law enforcement and general conservation issues.

The latest workshop was held at Nakai, Lao, in April 2018. This included a field visit to Nakai Nam Theun National Protected Area, in an area where otters are known to be present, led by Chanthalaphone Nanthavong of Project Anoulak. During this trip signs of Asian smallclawed otters were found, together with the spraint and footprints of the Eurasian otter. This is believed to be the first time the latter has been recorded in the Protected Area and it also confirms the presence of the species in Lao.

The workshop brought together 36 people, mostly from the Agriculture and Forestry Office, who are responsible for conservation issues in Lao. At the end of the workshop a Lao Otter Network was formed, linked to the IOSF Asian Otter Conservation Network, which has developed from previous workshops. The Lao Otter Network will identify priority areas for field surveys, conduct social surveys to assess any negative human-otter interactions, carry out more education and public awareness programmes, and investigate the scale of the illegal trade in otter furs and body parts and as pets. Chitpasong Senthammavong, of the Wildlife Management Division, was appointed the Network co-ordinator. As part of the workshop Paul Yoxon of IOSF met with Asoka Rasphone, Director of the Ministry of Foreign Affairs, who is supportive of otter conservation and the new Lao Otter Network.

We are grateful to the Anderson Rogers Foundation Inc., Action for the Wild, Nurtured by Nature, and the Rufford Foundation for financial support for the workshop. The full report on the workshop is available at http://www. otter.org/documents/InternationalWorkshops/International Workshop_Laos.pdf.

GRACE YOXON International Otter Survival Fund, Skye, UK Email grace@otter.org

\section{Participatory Octopus Market System Development strengthens community management of marine resources on Pemba Island, Zanzibar, Tanzania}

Fauna \& Flora International (FFI) has been working with NGO partner Mwambao Coastal Community Network since 2015, developing community-based marine resources management on Pemba Island, Tanzania. The work began with a remote fishing community on a small island to the south of Pemba, with capacity-building training sessions for the village fishers' committee. Following the training, the committee decided to implement a temporary closure of 100 ha of the island's reef flats. Catch data showed an increase in the average size of octopus caught when opening after a 3-month closure, but refraining from fishing remains difficult for low-income households. This represents a challenge for the fishers' committee working to retain consensus within the community, enforce closures and demonstrate the benefits of this management action to individual fishers and the wider community.

With Mwambao we explored various options for strengthening local governance and informing and empowering fishers in their relationship with buyers, including an investigation of how the existing market could be developed to support marine conservation and benefit the community. We adapted Practical Action's Participatory Market System Development tool in a conservation context and identified the kind of markets that would maximize conservation and social impact. After detailed consideration of four marine activities (octopus, reef fish, sea weed farming and other mariculture) scored against 20 impact criteria (e.g. gender inclusiveness, accessibility to different age groups, market demand and conservation benefits), the octopus fishery was prioritized for further development.

Mwambao's team was trained in the Participatory Market System Development approach and together with FFI acted as facilitators, encouraging participation of the market stakeholders in addressing challenges and highlighting converging interests to achieve long-lasting conservation and community impacts. Based on an earlier market research study we analysed a participatory market system, to identify and understand the power relations between key market actors such as local and intermediary buyers, agents and exporters, and fishers, who traditionally have low bargaining power. We organized meetings in three villages, to improve the community's confidence and their understanding of the market in preparation for a multistakeholder meeting that would bring together all market actors for a dialogue on opportunities and challenges in octopus fisheries.

We held a 2-day multi-stakeholder workshop in September 2017 in which the discussions amongst actors revealed information asymmetry in rural markets. Overfishing has resulted in a high proportion of small octopus in the catch which means that intermediary buyers' profits fall as only the larger octopus (above the legal size limit) can be sold for export. The buyers had been unaware of the fishers' committee's conservation initiatives and temporary closures, which they recognized as well aligned with their business interest of procuring export quality octopus. The community and fishers' committee also realized an opportunity to negotiate better terms for an opening days' catch, and to encourage buyers to make a financial contribution to the costs of the conservation efforts, such as that of patrol costs. Buyers and the fishers' committee agreed to 
meet before every opening day to negotiate a fixed price for the catch and a contribution per $\mathrm{kg}$ of octopus, to cover the committee's operating costs and to make a contribution to identified village development projects.

Since the workshop in September 2017 there have been a total of six openings following temporary closures across the three villages supported. At all opening days the fishers' committees collectively bargained fixed prices with local buyers. Opening day prices increased compared to prices observed on normal fishing days. In addition, the buyers' contribution for conservation now partially covers the committees' operating costs. This could be a sustainable finance model for longer term community-based conservation.

A further significant benefit of the market development work is the strengthening of the village fishers' committee as a village institution responsible for the sustainable use of marine resources. Community members have delegated the committee to negotiate on their behalf, and higher prices reinforce the roles and benefits of this village institution, with the community now seeking active participation to increase transparency and accountability.

KIRAN MOHANAN and TANGUY NICOLAS Fauna \& Flora
International, Cambridge, UK
E-mail kiran.mohanan@fauna-flora.org

LORNA SLADE Mwambao Coastal Community Network, Stone town, Zanzibar, Tanzania

\section{Fauna \& Flora International expands strategy on marine plastics}

In June 2018 the UK's microbead ban came fully into force. The legislation developed by the UK Department for Environment, Fisheries and Rural Affairs marked the culmination of efforts by a coalition of NGOs, including Fauna \& Flora International (FFI), to address this source of avoidable microplastic pollution across the UK.

Used in a wide range of consumer products, including rinse-off toiletries such as facial scrubs, shaving products and toothpastes, microbeads (microplastic particles) are known to pass through wastewater treatment and enter the sea, where their size makes them immediately available to filter feeders (Tanaka \& Takada, 2016, Scientific Reports, 6,34351 ). FFI has engaged with this issue since 2009 , has compiled a database of $>1,500$ products to identify those containing microplastic ingredients and developed a set of guidelines to inform robust national bans and corporate policies on microbeads (https://api.faunaflora.org/wp-content/uploads/2018/o6/Microbeads-GuidanceDocument.pdf). These guidelines were used to inform the UK microbead legislation and are now being shared more widely, with a simplified briefing for their use being made available for other countries or companies considering such action.

On the basis of this achievement, and in line with the current upsurge in public and political interest in plastic pollution, FFI has launched a revised and expanded strategy to guide its ongoing work to tackle marine plastics. FFI recognizes the many threats plastic poses to marine life (including entanglement in abandoned fishing gear and the impact of ingestion of plastic pieces) and also has specific concerns about the potential for microplastic pollution to introduce hazardous substances into the marine food chain.

This new strategy has a stronger focus on FFI's international role in supporting the development of local initiatives to target marine plastics, particularly in countries where plastic pollution is most problematic. We recognize that management of plastic waste presents specific challenges in the context of emerging and developing economies, and are looking for solutions to deal with the consequences for ocean pollution and human health through reduction at source rather than just focusing on clean-ups. Scoping work for interventions is under development in Cambodia, Indonesia, Honduras, Kenya and Belize. In addition, we are actively supporting the Commonwealth Clean Oceans Alliance (https://www.gov.uk/government/ news/commonwealth-unites-to-end-scourge-of-plastic), a group of Commonwealth nations working together to address plastic pollution, convened by the UK and Vanuatu. This provides a means for countries to share expertise, access resources where needed and develop joint commitments to act on plastics.

However, FFI also retains a strong focus on preventing direct sources of microplastic pollution (plastic particles reaching the ocean at sizes $<5 \mathrm{~mm}$, such as microbeads, plastic pellets and microplastic fibres), given concerns about the potential for microplastics to introduce hazardous substances (either additives or sorbed chemicals) into the marine food chain. We continue to address the loss of preproduction pellets (so-called nurdles) to the environment, and are advocating a supply chain approach to their management. This would ensure that pellets are well handled by all companies who use, transport or otherwise handle them, against recognized standards and with clear objective monitoring and reporting. This approach for tackling pellet loss was mentioned in this year's EU Plastic Strategy (https:// ec.europa.eu/commission/publications/legal-documents-plasticsstrategy-circular-economy_en), at recent OSPAR (Convention for the Protection of the Marine Environment of the North-East Atlantic) meetings, and in the Plastics Charter issued as part of the $2018 \mathrm{G} 7$ communiqué (https://g7.gc. ca/wp-content/uploads/2018/o6/OceanPlasticsCharter.pdf). We continue to work with other NGOs, the plastics industry, retailers, standards bodies, investors and government on this issue. We have also started to identify ways in which we can help address the emerging challenge of microplastic 